\title{
A Study on Prevalence of Brucellosis among Children and Adolescents in Missan Province-Iraq
}

\author{
Mahdi A. Al-Musawi, PhD \\ Pediatric Nursing Department, College of Nursing/ University of Baghdad
}

\begin{abstract}
In Iraq, brucellosis is considered an endemic disease in human and animals despite the measures applied to control the disease. The study was performed to obtain the information about the disease from aspect the age, the region, the time, and the commonest clinical symptoms. The disease was diagnosed according to the clinical signs and symptoms and using Rose Bengal test in Al-Sadr Hospital. The high percent of the disease were recorded in male children (53.8\%), also the study recorded (43.1\%) of the infected children were in ages between 14 to 17 years, while the low percentage was recorded in the ages between 5 to 7 years in percentage (6.1\%). (39.4\%) of infected children their family have a tends to ranching in their houses, and (28.8\%) of children were consumed unpasteurized milk, while (15.5\%) of cases were in direct touch with infected and contaminated animals and their discharges during abortions. The disease was increased in months of spring and summer where the high percentage was recorded in April (26.1\%), while low percentage was found in January (5\%). Amara district was the most common infected region with brucellosis in children with percentage (35.5\%) followed by Kumait and Maymona districts in percent (23.3\%, 14.4\%) respectively. High fever, copious sweating, head ache and loss appetite were the most common symptoms that accompanied to Malta fever in children. Conclusion of this study there were high percentage of brucellosis in children especially in city center and rural regions in Missan governorate because high intensity of population and some of them have a tendency to rear the animals inside the houses, which demanded from specific authorities to take care for control on the disease especially in the animals that consider the main source for the disease.
\end{abstract}

Keywords: Prevalence, Brucellosis, Children

\section{Introduction}

Brucellosis is also known in Iraq as Malta fever (WHO, 2006). The term is derived from the place of the first case which was discovered in the island of Malta between British soldiers (Wyatt, 2009). This infection emerged as a disease due to the contributing cause of Brucella melitensis which was discovered in the year of 1887 by David Bruce (Corbel, 2006). Brucellosis is well-known as zoo-noses disease in the world and is most caused by Gram-negative bacteria type Brucella (Woldemskel, 2013).

In Iraq, the brucella affected the individuals and the animals altogether and in all governorates. In human, so many cases documented in different governorates; between the 2001 and 2003108 cases had been diagnosed in Baquba City (AlDilamy, 2010); while 166 cases were diagnosed in 2004 in Saladin province (Khuder, 2006) and the ratio of infected female was up to the percentage $96.6 \%$. After one year in 2005 several other cases emerged in other provinces such as were; 150; 88 and 50 cases in Babylon, Kirkuk and Najaf governorates respectively (Al- Zubaidy, 2008).

In various countries, brucellosis is considered a work-related malady, which might be rare in children. However, in Iraq, because it is spread from animals to humans in non-workrelated means, its occurrence within children is the same to within adults or much more than them (Al-Dilamy, 2010).

Typically, humans get illness by eating or drinking contaminated food and drinks, such as unpasteurized milk and dairy products, but could also inflicted with it through vaccination by straight touch with contaminated animals or their parts and rarely through work-related contact in microbiology laboratories (Dermott et al, 2013).
The Brucella might go through the body by digestive system, respiratory system or mucous coatings and integral skin. After that, it might stretch through bloodstream and the lymphatic structures to several other body parts where it contaminates and inflicts the tissues and might affect local diseases (Sofian et al., 2013).

The Brucella melitensis is capable to flight phagocytic killing throughout hindering the phagosome-lysosome fusion and repeating inside macrophages (Young, 2009).

Following a changeable incubation phase ranging from less than one week to quite a few months, non-specific systemic warning signs such as pyroxia, headaches, weakness, night sweats and joint pains follow, resembling a flu-like sickness. Throughout the early phase of the infection, patients are often bacterimic that has a permanent model, making moving Brucella effortlessly noticeable by blood tests. Once in the blood stream, the Brucella is started to manifold organs/ systems, particularly those prosperous in reticuloendothelial tissue, such as liver, spleen, skeletal and hematopoietic system (Poester et al., 2013)

In children, clinical signs and symptoms of brucellosis are similar to adults, where the clinical presentations of human brucellosis variety from unclear and constitutional symptoms, such as lengthened pyroxia, anorexia, or exhaustion to local organ concern, like arthritis and neurobrucellosis. However, in children being unfamiliar with the disease may be a delay in diagnosis (Tuffah,J.A.(2008).

By early diagnosis and effective treatment, many of these patients recover without any persistent complications. Given the high prevalence of brucellosis in Iraqi children and the importance of diagnosing the asymptomatic patients, this study examined the occurrence of brucellosis in 


\section{International Journal of Science and Research (IJSR) \\ ISSN (Online): 2319-7064}

Index Copernicus Value (2015): 78.96 | Impact Factor (2015): 6.391

asymptomatic children seven to twelve years old in Kahak in Iran (Sofian et al., 2013).

Treatment was continued for 4-8 weeks until there was an improvement in symptoms and a 4-fold decline in serologic titers. All treated patients were asked to have regular weekly follow-ups and serologic studies. Once clinical and serologic improvement was evident, cases were visited every 3-4 weeks and as needed thereafter.

The main objectives of the current study are to throw some light on the incidence of brucellosis among children and adolescents with evaluate the clinical manifestations and laboratory findings.

\section{Methodology}

The current study was carried out from January $2^{\text {nd }}$, to June $3^{\text {rd }}, 2015$. The data and blood samples were taken from 180 child and adolescent who were diagnosed as infected with brucellosis. Those children and adolescents aged between five to 17 years and with average (12.5) year. The patients were diagnosed with brucellosis according to case history and clinical examination, The blood samples were taken from the patients for serology by using Rose Bengal test (simple and rapid test developed for detection of Brucella antibodies in human and animal sera through agglutination that occur between Brucella abortus S-99 and antibodies type IgM and IgG in patients'serum (Sofian et al., 2008). The tests were performed by using Rose Bengal Kit produced by Omega Diagnostic company (Scotland)and contain Brucella abortus S-99 killed by heat and treated by phenol 5\% and Tri-HCL in PH 3.62 and stained with Rose Bengal dye.2-ml blood samples were taken from the patients and the serum was separated by centrifugation method at $3000 \mathrm{rpm}$ for five minutes. The collected serum was stored at minus eighteen degree centigrade until it was analyzed. The test was achieved by supplying $50 \mathrm{ul}$ of each serum by micropipette to be tested to an enamel platter. The similar quantity of Rose Bengal antigen was appended to each serum sample and mixed up and shacked by hand for four minutes, and the test result was then read. Agglutination came into view as weak positive, positive, strong positive, or very strong positive.

\section{Results and Discussion}

The study was performed to obtain the information about the disease from aspect the ages, the regions, the months, the commonest clinical symptoms. The disease was diagnosed children and adolescents according to the clinical signs and symptoms and using Rose Bengal test. the results observed strong and clear agglutination for some cases may be due to high titration of antibodies and strong stimulation of Blymphocytes. Al-Thawani (2000) was refereed that the Rose Bengal test used to detection the brucellosis even in low titration of antibodies and we can determine early stages of the disease due to presence antibodies type $\operatorname{IgM}$ in acute stage and $\mathrm{IgG}$ in chronic of the disease.

The result observed that the majority of childhood brucellosis cases were boys in percentage (53.8\%), while the females were $(46.1 \%)$ of all cases, Fig (1).

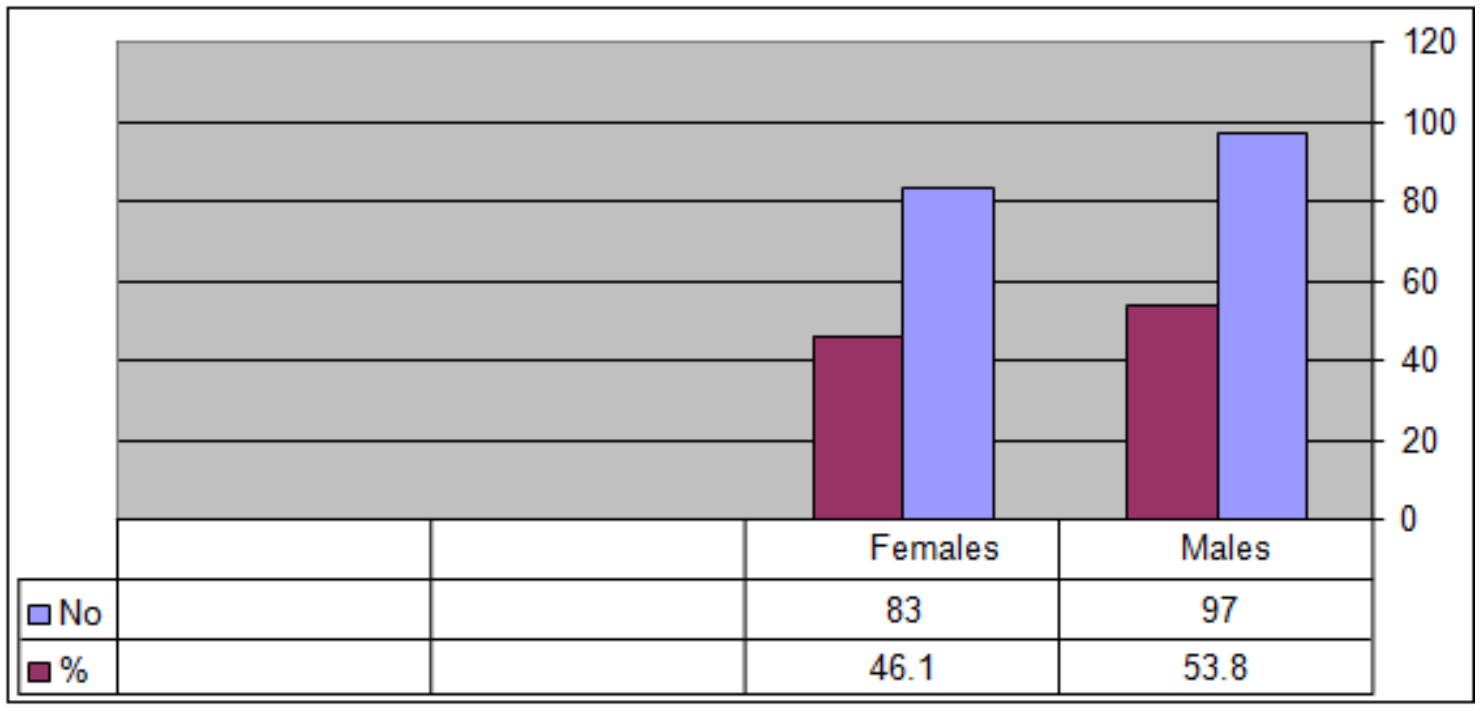

Figure 1: show the total number of the males and females children and adolescents infected with Brucellosis

This result agreed with another epidemiological study in the different regions over around the world, where in a study was performed in Serbia in years between 1980 and 2008 on 1521 person infected with brucellosis, found the males more infected than the females because the males was direct contact with domestic animals than the female during lactation and parturition (Cekanac et al., 2010).

Al-Hussain,and Thaer SH.(2012) reported that the human females had higher incidence than human males. This result might be due to that the human females are more involved in handling of farm animals. These females may be greatly exposed to the danger of contagion throughout straight contact with animals, utilization of unprocessed milk and dairy products. Furthermore, other rural practices in country sides which are at high risk for human beings for instance skinning of stillborn lambs and their broods, in addition to cutting the umbilical cord of newborn lambs and kids with teeth could also be causative reasons. But this study did not agree with Tufah (2008) which found the females more 


\section{International Journal of Science and Research (IJSR) \\ ISSN (Online): 2319-7064}

Index Copernicus Value (2015): 78.96 | Impact Factor (2015): 6.391

infected than the male in study performed on 100 patients in Al-Kut City by using Rose Bengal test.

In present study, the majority of childhood brucellosis cases were boys, there are some thoughts to clarify this highly male prevalence; boys more contact with animals than girls and eat contaminated foodstuffs but the study found no important difference between boys and girls in the route of disease.
The data observed high incidence of brucellosis in children and adolescents with the ages between (14 -17) years represented by $(43.1 \%)$ cases, followed by the ages between (11-13) years represented by $(31.1 \%)$ cases and the low percentage infected with disease were the ages between (5$7)$ years in $(6.1 \%)$ cases, Fig. (2).

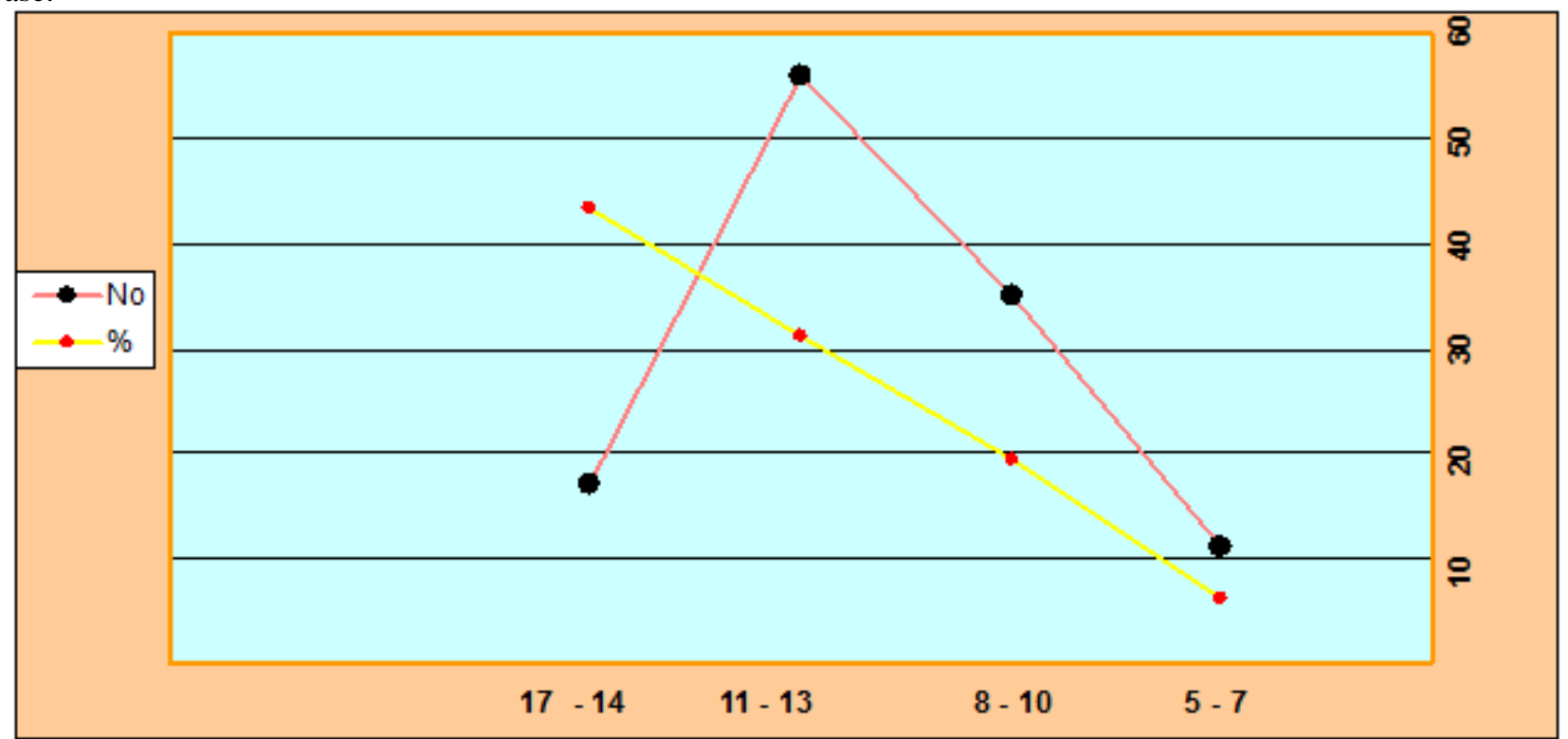

Figure 2: The distribution of Brucellosis among the patients according to the different ages for the children and adolescents

This study agreed with Doganay and his colleagues (2013) in study was performed in Iran, where found that the younger boys in adolescent stage more susceptible to infected with brucellosis especially in country sides and work-related contact with animals was inevitable; so, elder children might be at growing danger of contact with the infected animals. But the current study does not agree with another study performed in California in the USA which found increase brucellosis infection with ages between 55 and 64 years due to consumption of unpasteurized dairy products or contact with domestic (Al-Dewan, A. B. T. (2007).

Cekanac et al. (2010) were reefer the most common ages infected with brucellosis in between 30 and 49 years. In Germany not found any relationship between ages and inaction with brucellosis, therefore the disease considers un occupational disease (Dahouk etal, 2007).Samaha et al. (2008) found high prevalence of brucellosis in human and form (8\%) in Egypt due to direct contact with infected animals and half of the patients were from farmer families and rural areas.

The study observed that the most rural families have domestic animals in their houses $(39.4 \%)$, while $(15.5 \%)$ of infected patients were in direct contact with infected animals and their secretions during abortions and $(5 \%)$ were not in direct contact with infected animals, $(28.8 \%)$ acquired the infectious agents from consumption raw milk (unpasteurized) and homemade feta cheese, $(11.1 \%)$ of the patients were not consumed unpasteurized milk and their products which came from infected animals with Brucella spp.

\begin{tabular}{|c|c|c|}
\hline Type of lesion & $\begin{array}{c}\text { Number of } \\
\text { cases }\end{array}$ & Percent \\
\hline Breeding of animals in the house & 71 & 39.4 \\
\hline Direct contact with infected animals & 28 & 15.5 \\
\hline Not contact with infected animals & 9 & $5 \%$ \\
\hline Consumption raw milk (unpasteurized ) & 52 & 28.8 \\
\hline Not consumed unpasteurized milk & 20 & 11.1 \\
\hline
\end{tabular}

Tab (1) represent infected children and adolescent whose contact and consumed raw milk (unpasteurized) and their products of infected animals with Brucellosis.

Human infection is usually acquired by taking the unpasteurized, contaminated dairy products; direct contact with infected animal parts, and/ or inhalation of infected aerosolized particles and individual to individual transmission is less common (Doganay, 2013).

In a study performed in Hamadan in west Iran observed high infected percentage in children as a result of a direct contact with infected animals, also add the climate condition in Hamadan city may be play important role for distribution and developing the disease in rural areas (Sofian et al, 2008)andAl- Hussain et al., 2012). found high infection with Brucella Spp in country side areas in compared with urban areas due to direct contact with infected animals and their products.

Zamani et al (2011) reefer the human may be take the infection through direct contact with aborted and infected animals,or indirect through their products as raw milk and cheese,also add the organism seldom live in the acidic $\mathrm{PH}$ especially in fermenting batter and cream more than three months. 


\section{International Journal of Science and Research (IJSR) \\ ISSN (Online): 2319-7064 \\ Index Copernicus Value (2015): 78.96 | Impact Factor (2015): 6.391}

In the south of Iraq there is city called Missan, this city is famous of marshes and buffaloes, in this city, 266 cases were recorded from 2009 to 2011, this is as a result of the nature of the rural city and tendency of many people to keep the animals indoors (Mraisel, 2013).

In the present study, the researcher observed that the children and adolescent whose life in rural areas are more susceptible to infected with brucellosis due to direct contact with aborted animals and handle newborn lambs or kids born from infected dams, where most of school age children often help their families with flock management.

Fig (3) revealed most infected cases were reported in spring and summer especially in (March, April, May, June) and high percent was reported in April (26.1\%), followed byMarch and May with percent $(21.6 \%, 17.7 \%)$ respectively, while low percent was reported in January $(5 \%)$

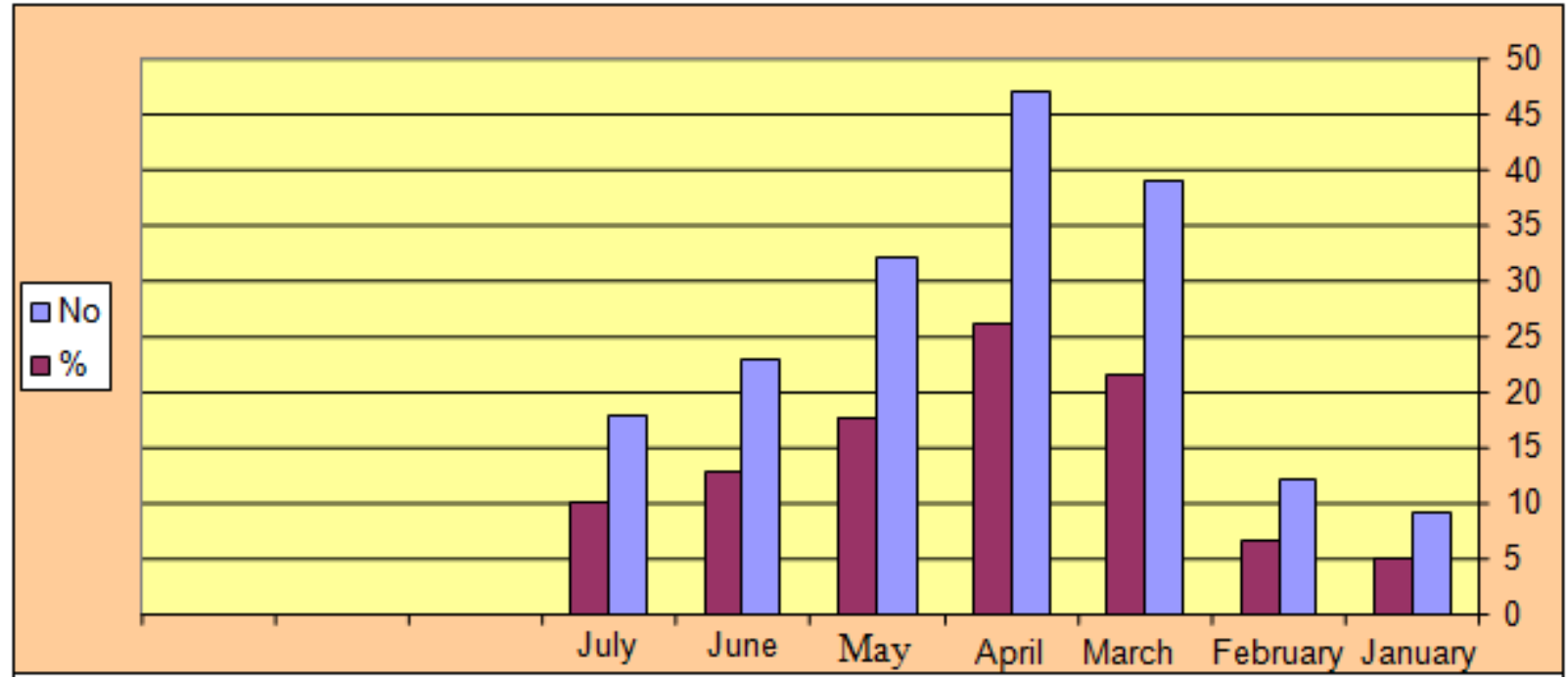

Figure 3: Distribution if infected cases according to the season and months in the year

This result was agreed with study was performed in Jordan by Shang et al., (2002), where found the seasonal infection with brucellosis increased in Spring and Summer due to increase in new born in animals, thus increase exposure to aborted animals due to brucellosis. Khuder (2006) refer the high percentage with brucellosis in Iraq increase in Spring and Summer and the first infected wave observe in first Spring (March and April)due to increase the new born between sheep and goats and increase contact the patients with aborted animals, while the second wave in May and June due to increase milking level between the animals.

Cekanac et al (2010) reported high infected percent with brucella in Serbia in month between February to March due to direct contact with aborted animals especially sheep and goats. The outbreak peak occurs from February to July and is directly related to the months connected to animals and humans delivery and abortion, occurrence of the disease is high (39.5\%) in summer season (Shang et al., 2002).
Notifications of human brucellosis, which are compulsory in Italy, reach a peak between April and June. Nevertheless, taking into account the standard incubation period of 2-4 weeks, and the fact that lamb slaughter is conventionally at a peak during the Easter time, it might be expected that workrelated exposure would result in a peak of human cases between March and May. The observed peak between April and June could be related to the manufacture and consumption of fresh cheese, initial just after lamb slaughter (De-Massis et al., 2005).

Amara district was report the most common infected region with brucellosis in children with percentage $(35.5 \%)$ followed by Kumait and Maymona districts in percent $(23.3 \%, 14.4 \%)$ respectively, fig (4). 
International Journal of Science and Research (IJSR)

ISSN (Online): 2319-7064

Index Copernicus Value (2015): 78.96 | Impact Factor (2015): 6.391

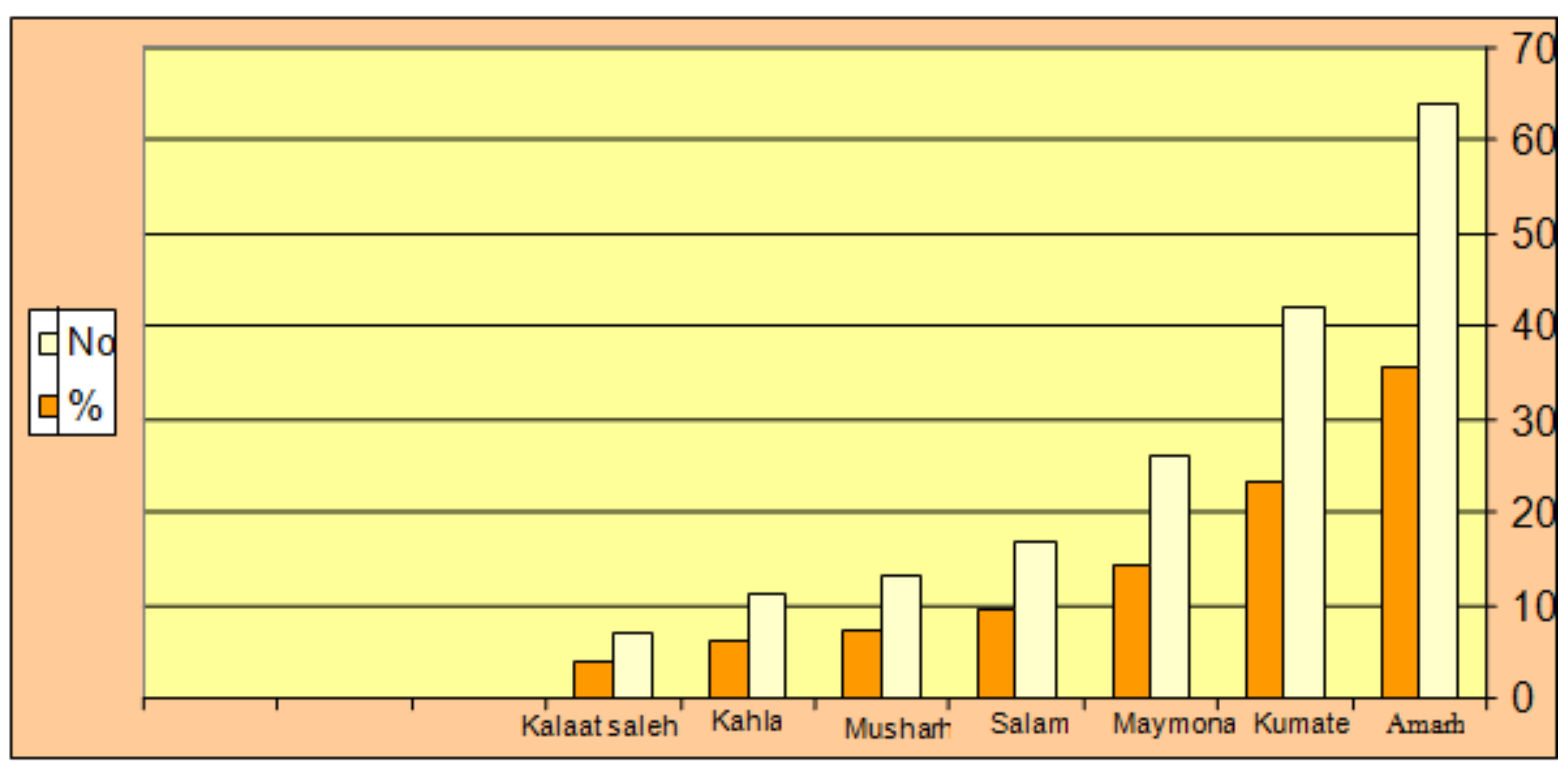

Figure 4: Show number and percentage of infected children with brucellosis in different regions in Missan governorate

The results in this study may be due to high distribution of the population in Amarh City and most of their families have animals in their houses and eating their products such as milk and their products without pasteurization (heat treatment). Also, the hot climate in south Iraq may play major role for developing the disease in Missan province especially in Spring and summer seasons.

Al-Hussain and Thaer (2012) revealed thatthere were many reasons that could affect the infection of brucellosis with a range of kinds of livestock such as weather circumstances, natural features, species, sex, age and diagnosis tests applied (26), many cases of brucellosis in animal reported in Iraq for different type of livestock, in seven provinces of middle and south Iraq (Baghdad, Salah-Eldin, Wasit, Babil, Thiqar, Missan \&Basra).
Zamani et al (2011)refer the brucella found high prevalence in developing countries and consider big problem on the public health and the percentage may be reach to $(80 \%)$ in dairy products fields especially in Punjab in India.

Study was performed by Sharrif (2006) on (266) patients by using Rose Bengal test found 60 (26.5) of them infected with brucellosis. The present study also observed high fever consider the most common symptoms accompanied brucellosis in children and adolescents (72.2\%), sweating $(65.5 \%)$, headache $(53.8 \%)$,loss appetite $(53.8 \%)$, while orchitis and arthritis were not reported in children and adolescents, Fig ( 5).

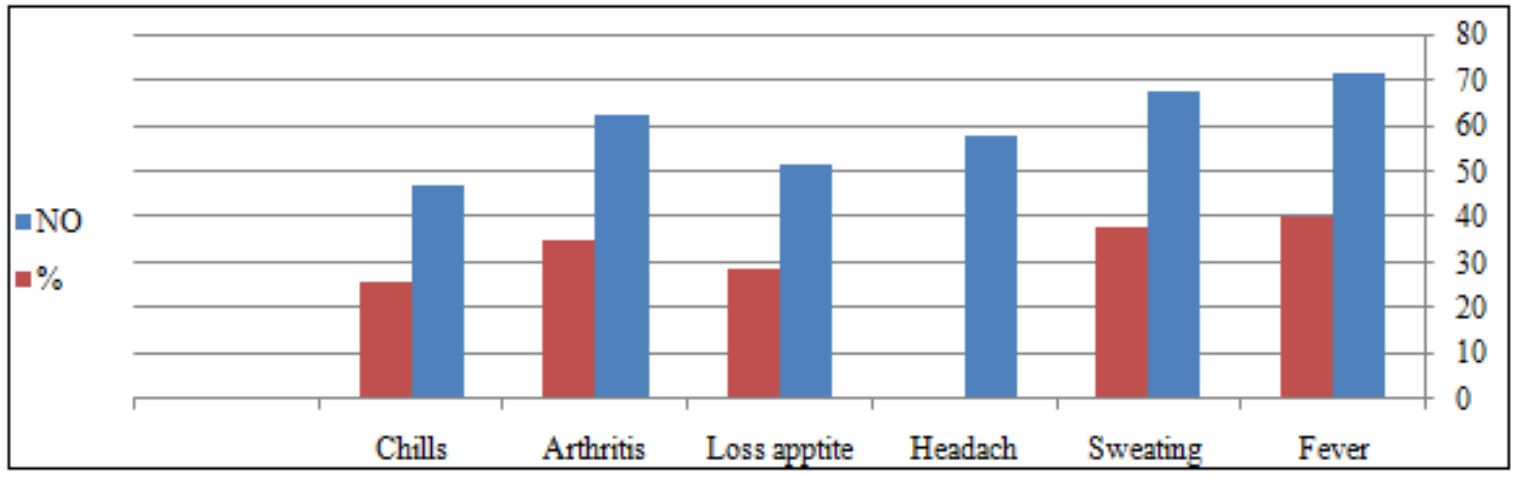

Figure 5: Clinical signs and symptoms observed in the children and adolescent infected with brucellosis

This results agreed with Al-Nuaimi (2007) where observed most of signs and symptoms accompanied increase fever,sweating during the night times, chills, arthritis, especially in Sacroiliac join, knee, and ankle joint.

Incubation period of the disease between 2-3weeks and the acute phase may found in most patients infected with brucellosis with non-specific symptoms include fever, sweating especially during the night, headache, loss appetite and arthritis. The range of fever are different during long times there for the disease some time called undulating fever (Corbel, 2006). Zamani et al (2011) refer the chronic stage of the disease may not accompanied by symptoms, sometimes with undulating fever, and the death may occur with $2 \%$ with untreated case due to pericarditis.

Conclusion of this study is that the brucellosis is wide spread zoonosis disease in Iraq among human especially in children and adolescents, and the infection is higher in males than females, this is because they have more contact with the infected animal and the animal products that uses in cooking like (milk, meat, contaminated food, dairy products). 


\section{International Journal of Science and Research (IJSR) \\ ISSN (Online): 2319-7064}

Index Copernicus Value (2015): 78.96 | Impact Factor (2015): 6.391

The disease appeared to be most common in city center (Amarh) in Missan governorate because high intensity of population and some of them have a tendency to rear the animals inside the houses, which demanded from specific authorities to take care for control on the disease especially in the animals that consider the main source for the disease and the study recommends that the local authorities should apply Health Programs principle involve three trends (animal, human, and environment) that effort together to get best result, this is implemented through a network of veterinarians, farmers and consumers and public health professionals to get a wide-ranging and entire information about the disease.

\section{References}

[1] WHO/OIE/FAO/CDS. (2006) Brucellosis in humans and animals. 7:1-66.

[2] Wyatt HV. (2009). Brucellosis and Maltese goats in the Mediterranean. Journal of Maltese History:1(2).

[3] Corbel, M.J. (2006). Brucellosis in humans and animals. WHO Library Cataloguing in Publication Data.

[4] Woldemeskel M, Zoonosis (2013). due to Brucella suis with special reference to infection in dogs (Carnivores): A Brief Review.Open Journal of Veterinary Medicine;3: 213- 221.

[5] AL-Dileamy BNS. (2010) Across-sectional study of brucellosis in patients admitted to Baquba to general hospital. The Iraqi Postgraduate Medical Journal;.9(1).

[6] Khuder HS.(2006)The incidence of Brucellosis in Salahddin governorate.Tikrit Journal of Pure Science $; 11(1)$.

[7] Alzubaidy KG.(2008) Sero - epidemiological study of brucellosis among patients with pyrexia of unknown origin in Najaf governorate. Kufa Med.Journal ;11(1).

[8] McDermott J,Grace D, and Zinsstag J.(2013) Economics of brucellosis impact and control in lowincome countries. Rev sci tech Off int Epiz. 32 (1): 249261.

[9] Sofian.M, Safaeipour.L, A. Aghakhani.A.(2013). "Screening of family members of patients with acute brucellosis in an endemic area of Iran," Iranian Journal of Microbiology, vol. 5, no. 3, pp. 215-219.

[10] Sofian.M, Aghakhani.A, Velayati.A, Banifazl.M, Eslamifar.A, and Ramezani.A.(2008). "Risk factors for human brucellosis in Iran: a case-control study," International Journal of Infectious Diseases, vol. 12, no. 2, pp. 157-161.

[11] Young EJ.(2009) Brucellosis. In: Feigin,Cherry, Demmler, Kaplan (eds). Textbook of Pediatric Infectious Diseases. 6th ed. Philadelphia: Saunders., Pp:1678-83.

[12] Poester FP, Samartino LE, Santos RL.(2013) Pathogenesis and pathobiology of brucellosis in livestock. Rev sci tech Off int Epiz;32 (1):105-115.

[13] Tuffah,J.A.(2008).Diagnostic and Serological Study on Brucella melitensis isolated from Human and Animals in Wassit province. M. Sc. Thesis, College of Veterinary medicine. University of Basrah.

[14]Al - Thawani, A.; Al - Bayatti, S.; Abass, A. and Abdul-Hussin, T. (2000). A study in the Epidemiological of Brucellosis in some production animals in the Province of Baghdad. The Vet. J., $\underline{10}$ (1): $168-174$

[15] Čekanac, R .; Mladenović, J.; Ristanović, E .(2010). Epidemiological Characteristics of Brucellosis in Serbia, 1980-2008. Croat. Med.J; 51(4): 337-344.

[16] Al- Hussain EJA, Thaer SH.(2012) Serological study on diagnosis of brucellosis in buffaloes in middle and south of Iraq. Anbar Journal of Veterinary Science 2012; 5 (2)(Arabic).

[17] Doganay GD, Doganay M.(2013). Brucella as a potential agent of bioterrorism.Recent Pat Antiinfect Drug Discov 2013;8(1):27-33.

[18]Al-Dewan, A. B. T. (2007). The occurrence of Brucellosis in Basrah City. M.Sc. Thesis, College of Veterinary medicine., University of Basrah.

[19] Dahouk SA, Neubauer H, Hensel A, Sch neberg I, Neckler K, Alpers K, et al.(2007) Changing epidemiology of human brucellosis, Germany, 19622005. Emerg Infect Dis;13(December (12)):1895-900.

[20] Samaha, H.; Al-Rowaily, M.; Khoudair, R. M.; Ashour, H.M.(2008). Multi center Study of Brucellosis in Egypt. Emerg Infect Dis;14(12): 19161918.

[21] Zamani, A.; Kooraki, S.; Mohazab, RA.; Zamani, N.; Matloob,R.; Raeeskarami,SR.(2011). Epidemiological and clinical features of Brucella arthritis in 24 children. Ann Saudi Med.31(3): 270273.

[22] Mraisel AJ. (2013)Epidemiological study of brucellosis infection rates in the province of Maysan. Journal of Dhi Qar Science ;4(1) (Arabic).

[23] Shang, D., X. Donglou and Y. Jiming (2002). Epidemiology and control of brucellosis in China. Vet. Microbiol., 90: 165-182.

[24] De Massis F, Di Girolamo A, Petrini A, Pizzigallo E, Giovanni A. (2005) Correlation between animal and human brucellosis in Italy during the period 19972002. Clin Microbiol Infect;11:632-6.

[25] Al - Nuaimi, A. E. S. (2007). Study of some aspects serological and genetic from a local isolates of the Brucella spp., Ph. D. Thesis., College of Science, University of Al-Mustansiriya. 